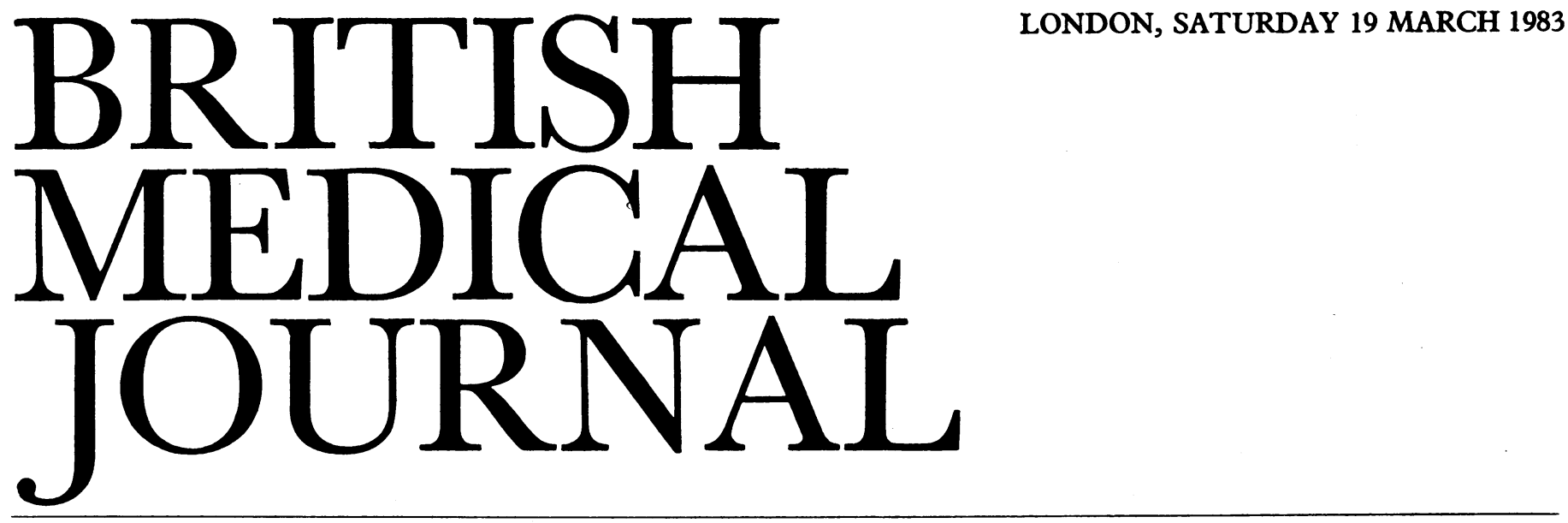

\title{
Diabetic maculopathy
}

Diabetic maculopathy is now a technical term more precise than a sick macula in a diabetic and may be defined as "visual loss due to macular oedema or hard exudates." Exudates occur most frequently in the outer reticular layers of the retina (for example, in the fibre layer of Henlé). ${ }^{2}$ They are formed from leakage of plasma lipoproteins and mucoproteins, as well as of fibrin, as a result of increased capillary permeability, perhaps in association with increased blood flow. ${ }^{34}$ Typically the exudates form segments of a circle around the macula, and particularly lateral to it. Over the years virtually the whole circle may be affected at one time or another. Death of neuronal cells with further deposition of lipids is probably secondary to the initial exudative lesion.

The relative freedom of the macula from haemorrhagic lesions is readily explicable by the lack of retinal capillaries over it, ${ }^{5}$ but the predisposition of this region to form hard (or waxy) exudates is not easily explained. Though nothing in retinopathy is absolute, diabetic hard exudates are rarely located in the radiating streaks often seen when hypertension is the primary cause. Hard exudates are readily distinguished from the soft white exudates of retinal infarction. Probably soft grey exudates are later phases of the latter; they may require use of the green filter on the ophthalmoscope to be seen easily. ${ }^{3}$ Soft exudates are much more variable with time than the hard.

Macular oedema is probably particularly dependent on increased capillary permeability. The more obvious are the exudates, the more common is macular oedema, but it may also be the sole cause of severe visual loss. It is perhaps the most difficult serious retinal lesion for the non-ophthalmologist to see, ${ }^{1}$ even after the obligatory pupillary dilatation. It appears as a hazy sheen with loss of definition of small vessels and increased reflectance from the surface, perhaps from swelling. Though macular oedema is potentially largely reversible, this depends on macular perfusion; if perfusion is poor the lesion (and so vision) fails to improve, even with better care of the blood sugar concentrations. ${ }^{6}$ Macular damage may impair sight much more insidiously than dramatic episodes of vitreous haemorrhage with intryening absorption.

Exudative maculopathy is typically seen in more elderly patients, often with non-insulin dependent (type II) diabetes, and may appear sooner after diagnosis of the disease-in contrast with the proliferative lesions most commonly appearing 10 to 25 years after recognition of insulin dependent (type I) diabetes. ${ }^{6} 7$ In a recent report $90 \%$ of patients with maculopathy were at least 30 years old when their diabetes had been diagnosed and almost $30 \%$ were over $60 .{ }^{7}$ When, however, macular oedema occurs independently of the usual perimacular hard exudates its clinical course is closer to that of proliferative retinopathy, perhaps because the appreciably increased vascular permeability contributes to both.

Increasing time from the diagnosis of diabetes is always the surest guide to increasing prevalence of diabetic tissue damage. ${ }^{3} 8$ Retinopathy reflects a probably general rule that duration is quantitatively more important the older the patient. ${ }^{9}$ Moreover, probably the various forms of hyperlipidaemia increase the likelihood of retinopathy, ${ }^{29}$ though the mechanism of this is difficult to disentangle from the variable extent to which hyperlipidaemia occurs in diabetics whenever hyperglycaemic.

The part played by raised blood glucose concentrations in retinopathy remains surprisingly controversial, particularly in view of the climate of near certainty a few years ago, when returning the blood glucose concentrations as nearly to normal as possible was canvassed as the only necessary preventive. But both "How near to normal is possible?" and "How near to normal is necessary ?" were questions never answered. Massive studies, exemplified by Pirart's, ${ }^{10}$ gave the overall picture that poor control of glucose was associated with a greater risk of retinopathy. Such studies, however, could be criticised as either retrospective or showing a massive loss to follow up over perhaps 20 years. They also addressed the relation by qualitative questions answerable only by "Yes" or "No" (since they used $t$ test or $\chi^{2}$ tests) and not with "How much ?" or "Over what range, with what gradient of risk?"

It was all the more shattering when two prospective studies with initial randomisation of their relatively small numbers between treatment groups gave no substantial support to benefit, firstly, from tight control of glucose concentrations over a year by continuous subcutaneous insulin infusion as opposed to the usual control by conventional (usually twice daily) insulin injection, ${ }^{11}$ and, secondly, from moderately improved mean concentrations of glycosylated haemoglobin achieved by intensified conventional diabetic treatment over two years as opposed to usual clinic treatment. ${ }^{12}$ Both studies recruited patients who had already developed background retinopathy between five and 15 years from the diagnosis of their diabetes. The benefit from continuous subcutaneous insulin infusion shown in some refined tests of retinal function was offset by an increased development of soft exudates, ${ }^{11}$ and this was confirmed in a separate, preliminary report..$^{13}$ 
Maculopathy has been widely distinguished only recently and has not been separately studied in analyses of risk factors such as hyperglycaemia or increased capillary fragility of the forearm skin. ${ }^{14}$ Nor has it been tested for correlation with hyperlipidaemia, though an increase in low density lipoprotein cholesterol alone (as well as total hypercholesterolaemia) has been found to be a risk factor for retinopathy as a whole. ${ }^{15}$ A longstanding Australian report ${ }^{16}$ that type II diabetics show more retinopathy if they are relatively insulin resistant has recently been confirmed from London. ${ }^{17}$

Treatments designed to lower or alter plasma lipid values reduce the size of perimacular hard exudates. Both low fat diets $^{18}$ and fat restriction with an increase in the proportion of polyunsaturated fatty acids ${ }^{19}$ have been associated with shrinkage of exudates, as was prescription of clofibrate without special dietary measures..$^{20}$ Vision was not improved, however, presumably because previous retinal destruction was irreversible. With retinopathy in general there is one report of preventive benefit from manipulating the dietary fat, ${ }^{21}$ and this result urgently requires further study with particular emphasis on exudative maculopathy. Cosmetic results have also been obtained by administration of para-aminosalicylic acid. ${ }^{22}$ Hypophysectomy, however, did not help maculopathy. ${ }^{23}$

Early reports of benefit from photocoagulation for maculopathy have now been handsomely confirmed. After MeyerSchwickerath ${ }^{24} 25$ introduced the technique for diabetic retinopathy this treatment was twice reported to decrease further deterioration in visual acuity. ${ }^{26} 27$ Then the first study in which the eye to be treated was randomly selected showed over an average of 26 months that untreated eyes deteriorated much more than treated ones. It also emphasised that eyes with an initial vision of $6 / 60$ or more did not benefit, ${ }^{28}$ as is almost inevitable from a treatment which prevents deterioration rather than causes improvement.

The latest report from the British multicentre study on xenon arc photocoagulation ${ }^{7}$ describes 99 patients with maculopathy; for inclusion in the study both eyes had to be similarly affected, and one eye was chosen at random for treatment to an extent determined by the ophthalmologist. During the five years of observation the treated eyes deteriorated on average less than one line of acuity while untreated eyes deteriorated by more than two lines $(p<0.01)$. The difference was greatest when the initial acuity was best $(6 / 6$ or $6 / 9)$, and in this study even patients with $6 / 36$ vision were not helped. In 13 diabetics both eyes went blind, but 26 untreated and six treated eyes were responsible for unilateral blindness. None of the various recorded clinical features affected the visual outcome (metabolic data were not analysed), but those who died had greater mean blood pressure than the survivors $(p<0.05)$. Vasoproliferative lesions were responsible for blindness in perhaps a quarter of the patients who lost their vision, so this must always be guarded against, even when retinopathy appears to be dominated by maculopathy.

If treatment seems successful when it only blocks further deterioration, preventive medicine is crucially important. Time from diagnosis of disease is of overriding importance in predicting the development of tissue damage. The time from the first appearance of substantial hyperglycaemia may well prove to be even more important, as hinted by the influence of high blood glucose concentrations at diagnosis on the deterioration of the vibration sensory threshold in the feet in patients with type II diabetes. ${ }^{29}$ In the recent British study some retinopathy was present at diagnosis in a fifth of those later studied because of maculopathy. ${ }^{7}$ Evidence is growing that community screening for diabetes (or hyperglycaemia) is a pointer to treatment as well as an academic exercise, because maculopathy typically affects late middle aged or elderly type II diabetics.

Consultant Physician,

T D R HockadaY $\stackrel{\frac{\Phi}{c}}{c}$

Radcliffe Infirmary,

Oxford OX2 6HE

${ }^{1}$ Kohner EM, McLeod D, Marshall J. Diabetic eye disease. In: Keen H, Jarrett J, eds. Complications of diabetes. 2nd ed. London: E Arnold, 1982:19-108.

2 Esmann V, Lundbaek $\mathrm{K}$, Madsen $\mathrm{PH}$. Types of exudate in diabetic retinopathy. Acta Med Scand 1963;174:375-84.

3 Jensen VA, Lundbaek K. The eye in diabetes mellitus. In: Pfeiffer EF, ed. Handbook of diabetes mellitus. Vol 2. Munich: Lehmanns, 1969: 659-81.

+ Goldberg MF. Natural history of diabetic retinopathy. Chicago Medicine $1972 ; 75: 1015-8$.

5 Hogan MJ, Alvarado JA, Weddell JE. Histology of the human eye. An ڤँ atlas textbook. Philadelphia: WB Saunders, 1971.

6 Ticho U, Patz A. The role of capillary perfusion in the management of diabetic macula edema. Am $\mathcal{F}$ Ophthalmol 1973;76:880-6.

${ }^{7}$ Kohner EM, Gatlin W, Leaver PK. Photocoagulation in the treatment of diabetic maculopathy. Ophthalmology (in press).

${ }^{8}$ Kahn HA, Bradley RF. Prevalence of diabetic retinopathy. Age, sex, 3 and duration of diabetes. Br f Ophthalmol 1975;59:345-9.

- Larsson Y, Sterky G, Christianson G. Long-term prognosis in juvenile diabetes mellitus. Acta Paediatr Scand 1962;51, suppl 130:1-76.

10 Pirart J. Diabète et complications dégénératives. Présentation d'une étude prospective portant sur 4400 cas observés entre 1947 et 1973 (troisième et dernière partie). Diabete Metab 1978;3:245-56.

11 Lauritzen T, Frost-Larsen K, Larsen HW, Deckert T. Metabolic regulation, retinal function and retinal morphology during one-year $G$ treatment with continuous subcutaneous insulin infusion (GSII) and $\mathrm{O}$ conventional therapy (CT): a randomized prospective study. Diabetologia $\vec{\oplus}$ $1982 ; 23: 183$.

12 Holman RR, Dornan TR, Mayon-White V, et al. Two-year prospective study of improved diabetic control in insulin-dependent diabetic patients with background retinopathy. Diabetologia $1982 ; 23: 175$.

${ }^{13}$ Hooymans JMM, Ballegooie EV, Schweitzer NMJ, Doorenbos H, Reitsma WD, Sluiter WJ. Worsening of diabetic retinopathy with strict control of blood sugar. Lancet $1982 ; \mathrm{ii}: 438$.

14 Hunter PR, Bloom A, Kelsey JH, Porter R. Cutaneous capillary resistance and retinal haemorrhage in diabetes. Diabetologia $1971 ; 7: 20-4$.

15 Dornan TL, Carter RD, Bron A, Turner RC, Mann JI. Low density lipoprotein cholesterol: an association with the severity of diabetic retinopathy. Diabetologia 1982;22:167-70.

${ }_{16}$ Stocks AE, Martin FIR. Insulin sensitivity and vascular disease in maturity-onset diabetics. Br Med f 1969 ;iv:397-9.

17 Maneschi F, Foley K, Mashiter K, Bloom SR, Alberti KGMM, Kohner EM. Metabolic and hormonal factors in the pathogenesis of retinopathy in type II (non-insulin dependent) diabetes: insulin resistance, residual insulin secretion, intermediate metabolites, growth hormone, prolactin, gastro-intestinal hormones. Diabetologia 1982;23:185.

18 Van Eck WF. The effects of a low fat diet on the serum lipids in diabetes and its significance in diabetic retinopathy. Am f Med 1959;27:196-211.

${ }^{19}$ King RC, Dobree JH, Kok D'A, Foulds WS, Dangerfield WG. Exudate diabetic retinopathy: spontaneous changes and effects of a corn oil $\delta$ diet. Br F Ophthalmol 1963;47:666-72.

20 Duncan LJP, Cullen JF, Ireland JT, Nolan J, Clarke BF, Oliver MF. A three-year trial of Atromid therapy in exudate diabetic retinopathy. Diabetes 1968;17:458-67.

${ }^{21}$ Houtsmuller AJ, Zahn KJ, Henkes HE. Unsaturated fats and progression $\mathrm{O}$ of diabetic retinopathy. Doc Ophthalmol 1980;481:363-71.

${ }^{22}$ Esmann V, Jensen HJ, Lundbaek K. Disappearance of waxy exudates in $N$ diabetic retinopathy during administration of p-amino-salicylate (PAS). Acta Med Scand 1963;174:99-104.

${ }^{23}$ Fraser R, Kohner EM, Joplin GF, et al. The place and the effect of pituitary ablation for diabetic retinopathy. In: Malaisse WJ, Pirart J, eds. N Diabetes. Amsterdam: Excerpta Medica, 1974:431-8. (Excerpta N Medica International Congress Series, No 312.)

24 Meyer-Schwickerath G. Light coagulation. Buech Augenarzt 1959;33: ㅇ $1-96$.

${ }^{25}$ Meyer-Schwickerath GRE, Schott K. Diabetic retinopathy and photocoagulation. Mod Probl Ophthalmol 1969;8:492-9.

${ }^{26}$ Koerner F, Schlegel D, Koerner U. Diabetic retinopathy study. Preliminary results from 215 patients treated uniocularly with photo- $\frac{T}{0}$ coagulation. Albrecht Von Graefes Arch Klin Exp Ophthalmol 1976; O 200:99-111.

${ }^{27}$ Rubinstein K, Myska V. Pathogenesis and treatment of diabetic maculo- $\overrightarrow{\mathbb{D}}$ pathy. Br f Ophthalmol 1974;58:76-84.

28 Patz A, Schatz H, Berkow JW, et al. Macular edema. An overlooked complication of diabetic retinopathy. Transactions of the American Academy of Ophthalmology and Otolaryngology 1973;77:34-42.

${ }^{29}$ Hockaday TDR, Hillson RM, Smith B. Correlates of deterioration in pedal vibration sensory threshold over 5 years from diagnosis of maturity onset diabetic patients. Diabetologia $1982 ; 23: 174$. 